\title{
Gêneros discursivos no ensino de japonês: material autêntico, tecnologia digital e motivação nos níveis iniciais
}

Flávio Ricardo Medina de Oliveira,

Universidade Federal do Paraná

\begin{abstract}
Resumo
Neste artigo, levantamos a hipótese que problemas no atual formato da vasta maioria dos materiais didáticos de língua japonesa teriam um papel central no alto grau de desistência nos níveis iniciais. Apontamos, então, possibilidades para a melhoria de tal quadro, envolvendo gêneros textuais, material autêntico e tecnologia digital.

Palavras Chave: ensino de língua japonesa; gêneros textuais no ensino de L2; material autêntico.
\end{abstract}

\begin{abstract}
In this article we raise the hypothesis that problems in the current format of the majority of Japanese language teaching materials play a central role in the high degree of abandonment in initial levels. We point to possibilities for improving this panorama, focusing on genres, authentic materials and digital technologies.

Keywords: Japanese language teaching; genres in second language teaching; authentic material.
\end{abstract}

\section{INTRODUÇÃO}

É amplamente reconhecido que o aprendizado da língua japonesa é de grande dificuldade para falantes nativos de línguas românicas. As causas dessa dificuldade podem ser atribuídas à diferente ordem de termos na oração, marcação de casos na língua japonesa, léxico com poucas similaridades e diferentes códigos de escrita, apenas para citar alguns. Em suma, é comum que se atribua às diferenças linguísticas e notacionais das línguas portuguesa e japonesa a dificuldade dos brasileiros no aprendizado do japonês.

No entanto, se por um lado não podemos ignorar as dificuldades reais que advém de tais diferenças, por outro vemos que muitos cursos e professores se valem delas para defenderem o status quo dos materiais didáticos, a saber, de eixo essencialmente gramatical e conteúdo, na vasta maioria das vezes, de linguagem artificial e fora de contexto.

As dificuldades mencionadas também servem como a explicação mais comum para 
justificar os altos níveis de desistência nos cursos da língua. ${ }^{1}$ Não se cogita, em geral, que a forma como o japonês é ensinado possa ter um papel na queda da motivação inicial dos alunos.

No entanto, argumentamos que a natureza do material didático, como consequência de uma visão essencialmente estruturalista de língua e de ensino de língua, está intrinsecamente atrelada à queda da motivação do estudante de segunda língua. Afinal, é o direcionamento do conteúdo aprendido em sala que ditará, em grande medida, o que o aluno será ou não capaz de produzir ou compreender em termos comunicativos. Nesse sentido, vemos que a vasta maioria dos materiais atuais preocupa-se em fazer o aluno "colecionar" uma série de conhecimentos gramaticais, lexicais e de ideogramas, de forma descontextualizada, acreditando que é impossível atingir um nível de comunicação efetiva sem antes de ter uma ampla base desses conhecimentos estruturais. Espera-se que o aluno possa, após ter tido acesso a todos esses conhecimentos, simplesmente colocar as estruturas e léxico aprendidos em um uso pragmaticamente apropriado - apesar de ele nunca ter tido acesso à língua em usos concretos.

Argumentamos que uma mudança radical na visão de língua e de ensino de língua, e a consequente reformulação de material didático, é essencial para a transformação deste quadro. Mesmo nos níveis iniciais, com seus desafios de código de escrita e diferenças linguísticas, acreditamos ser de essencial importância trabalhar em função de permitir que o aluno se torne capaz de comunicação efetiva, tendo acesso à língua em uso, e não de forma artificial ou fora de contexto.

Este trabalho é, por um lado, o resultado de mais de dez anos de estudo da língua japonesa, seguidos de doze anos de docência e reflexão do autor sobre o ensino do japonês para brasileiros e de dois anos de ensino de prática e metodologia de ensino da língua na Universidade Federal do Paraná. Por outro, é o início de uma tentativa de sistematização e aprofundamento teórico dessas vivências, em uma tentativa de elaboração de um material que permita aos alunos vencerem de fato as dificuldades do aprendizado do japonês, rumo a uma capacidade efetiva de comunicação já desde os níveis mais iniciais do ensino.

Neste artigo, fazemos uma breve discussão de como conceitos importantes, como motivação no aprendizado de L2, gêneros textuais e material autêntico, podem ser aplicados

\footnotetext{
${ }^{1}$ Em uma breve consulta a três instituições de ensino com tradição e longa história de língua japonesa em Curitiba, obtivemos como resposta que nenhuma delas possui mais que $10 \%$ de seus alunos em níveis considerados "intermediários".
} 
ao ensino de língua japonesa. Estabelecemos, então, alguns direcionamentos para a confecção de um material que melhor atenda às demandas de aprendizado dos alunos da língua japonesa.

\section{A MOTIVAÇÃo NO APRENDIZADO DE L2 E O ENSINO DA LÍNGUA JAPONESA}

A motivação é um construto complexo e não há, de forma alguma, unanimidade a respeito de sua natureza. No entanto, os pesquisadores da área em geral concordam que ela não é um traço estável e imutável da personalidade, mas antes se trata de um processo psicológico que envolve tanto características próprias da personalidade do indivíduo quanto a percepção do ambiente ao seu redor e a respeito da tarefa a ser desempenhada (Lens et al. 2008). Dessa forma, seria possível influenciar (positiva ou negativamente) a motivação de um aluno, dependendo de como a tarefa lhe é apresentada e do ambiente de estudo (atitude do professor, ambiente físico de sala e natureza do material, apenas para citar alguns).

A motivação desempenha um papel importantíssimo no processo de aprendizagem de uma segunda língua, uma vez que há evidências concretas de que o "fracasso" ou rendimento insatisfatório está ligado, por diversas vezes, mais à falta de motivação do que à incapacidade cognitiva do aluno ou, por conseguinte, à dificuldade da tarefa em si (Boruchovitch, 1999).

Uma distinção que vários pesquisadores da área fazem em termos de motivação relaciona-se com a oposição entre motivação intrínseca e motivação extrínseca (Deci, 1975; Deci e Ryan, 2000). De maneira geral, a motivação extrínseca vem associada a recompensas externas para o indivíduo ao desempenhar a tarefa, como benefícios profissionais, reconhecimento de outrem ou evitação de castigos. A motivação intrínseca, por outro lado, estaria relacionada ao estímulo de fazer a atividade "por si mesma". Entrariam aí fatores como interesses pessoais, diversão, desenvolvimento pessoal, aquisição de conhecimento, sentido de autonomia e autoafirmação, por exemplo.

É também um consenso bem estabelecido que a motivação intrínseca é capaz de gerar melhores resultados no desempenho de uma atividade do que a motivação extrínseca, especialmente no caso do processo de aprendizagem (Brown, 2000, cap. 5), uma vez que é capaz de genuinamente manter o estímulo e a atenção do aluno desde nas pequenas tarefas a 
serem desenvolvidas em sala até no objeto de estudo como um todo.

No caso da língua japonesa, a experiência do autor e o relato de professores de três instituições de tradição em Curitiba apontam para o fato de que, há muitos anos, pouquíssimos são os alunos de descendência nikkei que buscam o curso por uma obrigatoriedade parental. Também nos últimos anos, assistimos a uma redução dramática no número de alunos que buscam os cursos com intenção de se tornarem decasséguis, ${ }^{2}$ devido a crises internacionais, demissão em massa de estrangeiros no Japão e valorização do real frente ao iene. Ao contrário, a consulta às escolas revelou que cerca de $50 \%$ dos alunos não são de origem nikkei, sendo que buscam o aprendizado da língua por razões pessoais, em especial o interesse na cultura tradicional e na cultura pop do Japão. Música, quadrinhos, animação, literatura moderna, contos tradicionais, danças folclóricas, a história do Japão (especialmente na figura de estereótipos como o samurai e a geisha), o estilo de vida e a ética de trabalho japonesa, ou ainda "a sonoridade" ou o caráter "exótico" da língua são alguns dos pontos que são levantados pelos alunos como razões para terem iniciado seus estudos de japonês.

Assim, vemos que, ao menos em termos de motivação inicial dos alunos, há uma inclinação muito maior para fatores de caráter intrínseco do que extrínseco. Diante desse quadro, é impossível não se perguntar o porquê de tão poucos alunos chegarem a níveis intermediários e avançados da língua. Sem dúvida, o fato do japonês ser estudado por "razões pessoais" pode ser, por um lado, um fator de abandono dos estudos quando outros fatores externos se fazem presentes (por exemplo, fatores econômicos ou de restrição de tempo). Por outro lado, argumentamos aqui que o mesmo fato pode tornar o aluno também mais sucetível a desestímulos de natureza pedagógica e metodológica: quando alunos interessados na cultura japonesa (em uma forma ou outra) vêem-se incapazes de acessá-la, apesar de anos de estudo, podem sentir um nível muito grande de frustração e virem a abandonar o curso. Naturalmente, em tal situção, tanto para professores quanto para alunos, o mais comum é atribuir às diferenças linguísticas e de escrita essa frustração. No entanto, como visto anteriormente, não é possível atribuir apenas a limitações cognitivas ou à dificuldade da tarefa seu fracasso na mesma, mas antes, fatores como a dificuldade

\footnotetext{
${ }^{2}$ Termo recentemente dicionarizado no português, oriundo da palavra japonesa "dekasegi", que indica descendentes de japoneses que vão ao Japão com a intenção de trabalhar por poucos anos e voltar ao Brasil com as economias conseguidas.
} 
percebida e os fatores ambientais do processo de aprendizado desempenham um papel primordial na queda de motivação do aluno.

\section{A MOTIVAÇÃO E OS MATERIAIS DIDÁTICOS DE LÍNGUA JAPONESA}

Apesar de considerarmos outros fatores ambientais de indiscutível relevância no ensino de japonês (por exemplo, a formação dos professores), neste artigo nosso foco será a natureza do material didático de língua japonesa.

Invariavelmente, o que vemos nestes materiais é uma clara predominância de um eixo gramatical que dita a organização de conteúdo, os exercícios propostos e os objetivos de cada unidade. Podemos citar, a título de exemplo, o "Minna no Nihongo" (3A Corp, 1998) e "Nihongo 1, 2, 3" (Kusakari et. al, 1996), materiais amplamente utilizado em Curitiba.

O objetivo de cada unidade constitui-se no ensino de um ou mais itens gramaticais, sendo que qualquer amostra de língua neles é claramente manipulada para atender a esses objetivos. Tomaremos como exemplo aqui a unidade de número 24 do livro didático "Nihongo 1, 2, 3" (op. cit), que tem por objetivo ensinar a forma volitiva de verbos em japonês. O conteúdo gramatical é bastante claro, e qualquer outro aspecto linguístico subordina-se a ele.

Os itens lexicais, por exemplo, são organizados em função desses objetivos gramaticais, com pouca unidade temática na maioria das vezes. Os novos itens lexicais apresentados na referida unidade são: namorado, país, querer, zoológico, processador de texto, PC, cansar-se, trabalhar, levantar-se e sentar-se.

Em geral, podemos dizer que inexistem exercícios que promovam o intercâmbio de informações e a interação autêntica, sendo que os "exercícios de conversação" se resumem a drills ensaiados previamente e a realização de perguntas e respostas propostas pelo livro. Novamente, na unidade que tomamos por exemplo, vemos as seguintes perguntas que devem ser feitas entre alunos ou pelo professor para os alunos: "O que você quer agora?", "você quer ir a algum lugar agora?", "você quer tomar algo quente agora?" e "você quer andar de trem-bala?", todas em um mesmo exercício, sem qualquer sequência lógica ou unidade temática - o único ponto comum é, de fato, a estrutura gramatical.

A leitura limita-se, na vasta maioria dos casos, à leitura silenciosa ou em voz alta de 
diálogos-exemplos ou pequenos textos, de não mais de um ou dois parágrafos, com "perguntas de interpretação" (de resposta bastante óbvia) ao final. Um dos diálogosexemplos que devem ser lidos em voz alta por dois alunos, e cumpre a função de "exercício de conversação" da unidade em questão, é:

"KIM: Que tipo de coisa você quer ter?

$\mathrm{AN}$ : Eu quero um processador de textos. E você?

KIM: Eu quero um PC."

Novamente, é possível observar a artificialidade do diálogo, além da impossibilidade de sua leitura fomentar qualquer tipo de habilidade comunicativa, exceto à de leitura dos códigos de escrita japoneses.

Exercícios de escrita, quando existem separados dos drills de gramática, limitam-se à construção de frases curtas (fora de contexto) ou de "redações" artificiais, de não mais de um ou dois parágrafos novamente.

No critério de código de escrita, há uma preocupação em ensinar os ideogramas do japonês em uma ordem claramente determinada pela facilidade de escrita. Há, também, uma clara ênfase em questões de caligrafia e escrita à mão, como ordem de traços, tipos e contagem de traços.

Não há qualquer tipo de exposição à linguagem autêntica, a textos autênticos ou oportunidades de comunicação autêntica. Cabe ao professor, então, esforçar-se em promover algum tipo de comunicação em sala e forçar aos alunos o uso das estruturas aprendidas, o que naturalmente é uma tarefa bastante difícil, em vista da forma como os conteúdos são organizados no material.

Argumentamos que a organização claramente estruturalista desses materiais dá poucas possibilidades de o aluno se desenvolver em direção à comunicação e interação efetiva em japonês, de forma que é natural ele apresentar grandes dificuldades de conversação ou de leitura de textos na língua, mesmo após anos de estudo. Assim, podemos supor que sua motivação irá diminuir drasticamente à medida que o tempo de estudo não corresponder à capacidade efetiva de comunicação, mas apenas à quantidade de estruturas e ideogramas "aprendidos". 


\section{O PAPEL DOS GÊNEROS DISCURSIVO-TEXTUAIS NO ENSINO DE JAPONÊS}

Partimos, nesse artigo, de uma visão bakhtiniana de gêneros textuais, de que é através deles que nos comunicamos em nossa vida prosaica, e que nenhuma enunciação acontece no vazio social ou histórico. Os gêneros constituem formas relativamente estáveis de texto (oral ou escrito), situadas histórica e socialmente, e com características mais ou menos previsíveis em termos de estrutura formal e funcionalidade (cf. Swales, 1990 e Marcuschi, 2002). Segundo Marcuschi, "nada do que fizermos linguisticamente estará fora de ser feito em algum gênero textual" (Marcuschi, 2005, p. 35), sendo que eles seriam de extrema utilidade para entendermos como se estabelecem relações sociais e a efetiva interação entre indivíduos, além de permitir o acesso a uma cultura estrangeira.

Destacamos que através dos gêneros é possível ativar o conhecimento prévio do aluno, permitindo que ele infira sobre estruturas textuais, elementos extratextuais e utilize seu conhecimento de mundo para refletir sobre a lógica de organização de um texto, sobre as intenções do autor e sobre como responder àquele texto.

Em particular, essas possibilidades são de extrema importância no caso da língua japonesa visto que, como já mencionado, há uma grande dificuldade inicial devido às diferenças linguísticas e de notação escrita. Ensinar o aluno a angariar o máximo de informações e aprender a fazer inferências a partir do contexto de produção torna-se ainda mais relevante, pois qualquer elemento extra é bem-vindo quando o código linguístico em si é tão desafiador.

Ao mesmo tempo, materiais cujo eixo gire em torno de gêneros podem ser organizados de forma a pensar quais são os elementos necessários para tornar um aluno habilitado para compreender e/ou produzir um determinado gênero. Por "elementos" podemos pensar em itens gramaticais, itens lexicais, questões culturais, informações sobre estruturação textual, ou ainda funções comunicativas, ou seja, não argumentamos a necessidade de abandono do ensino da gramática ou de vocabulário, mas sim que tais elementos sejam pensados como degraus ou ferramentas para se atingir uma comunicação efetiva, em particular no intuito de tornar o aluno capaz de interagir a partir de determinados gêneros discursivos.

Também acreditamos que essa mudança de foco deve necessariamente organizar o ensino da escrita do japonês: ao invés de ordenar os ideogramas por facilidade de escrita, é 
preciso pensar em quais deles se fazem necessários em determinado contexto de gênero discursivo-textual. Além disso, argumentamos que, na atualidade, a maior parte da produção escrita (seja em contextos formais ou informais) se dá através do meio digital - através de celulares e computadores -, de forma que a ênfase na caligrafia possa ser transferida para a capacidade de compreensão e de "escrita digital" ${ }^{3}$ dos ideogramas. Isso permitiria que os aprendizes pudessem, desde os níveis mais iniciais, aprender ideogramas mais relevantes para as suas necessidades, independentemente de sua dificuldade de escrita, além de permitir o aprendizado de um número muito maior de ideogramas em um mesmo espaço de tempo (uma vez que apenas sua leitura e significado são importantes, e não como escrevê-lo à mão).

\section{GÊNEROS DISCURSIVO-TEXTUAIS E MATERIAL AUTÊNTICO}

Finalmente, acreditamos ainda ser essencial substituir a linguagem artificial encontrada via de regra nos materiais atuais por uma linguagem autêntica, mais próxima do que é efetivamente usada na comunicação em japonês. Citando Kramsch, utilizamos o termo material autêntico em "oposição à linguagem artificial pré-fabricada dos livros-texto e dos diálogos institucionais; refere-se à forma não pedagógica de uso da linguagem em situação natural de comunicação" (Kramsch, 1993, p. 175).

Considerando nossa proposição de um material de eixo orientado por gêneros, acreditamos ser de ainda maior relevância a exposição dos alunos a materiais autênticos, na medida em que eles sejam capazes de interagir com exemplares reais de textos feitos de japoneses para japoneses.

Textos autênticos (desde formulários e receitas de culinária até artigos de revista e propagandas de TV) são evitados em salas de aula de japonês devido à dificuldade da língua, especialmente nos níveis iniciais. No entanto, acreditamos que com a devida preparação pedagógica e organização de material, é possível habilitar os aprendizes a confrontar exemplares reais de tais gêneros. Mais ainda, consideramos não apenas a possibilidade desse contato, mas a necessidade dele, pois é apenas através da exposição à forma como os japoneses se comunicam que os aprendizes poderão interagir, eles mesmos, na língua-alvo.

\footnotetext{
${ }^{3}$ Ao se escrever em japonês, faz-se uso de um teclado comum e digita-se, através do alfabeto românico, o texto desejado. O software do comutador ou celular oferece então, na tela, os ideogramas que possuem aquela leitura e cabe ao usuário escolher o ideograma apropriado para o que pretendia dizer. Assim, faz-se necessário um conhecimento da leitura de cada ideograma e de sua aparência para escrevê-lo no computador, mas não de como efetivamente escrevê-lo à mão (ordem de traços, tipos de traços, etc.)
} 
Defendemos, ainda, que o contato com tais materiais sejam de grande valia na manutenção e renovação da motivação intrínseca dos alunos, uma vez que eles poderão sentir que estão efetivamente se tornando capazes de atingir seus objetivos de interagir com falantes japoneses e acessar a cultura japonesa.

Nesse âmbito, apontamos o grande valor do uso das várias tecnologias digitais inseridas no contexto de sala de aula: aplicativos de celulares, blogs, redes sociais, vídeos, páginas de empresas, estabelecimentos, produtos e personalidades japonesas, apenas para citar alguns. O aluno pode preencher formulários, procurar receitas, acessar propagandas, participar de fóruns, visualizar mapas e organizar rotas de percurso, checar programações de cinemas ou ainda interagir em redes sociais, por exemplo. Um aluno que consiga realizar qualquer uma dessas tarefas em seu curso saberá que acabou de realizar uma tarefa que existe no mundo real, uma vez que interagiu com o mesmo conteúdo que um japonês utilizaria, e isso indubitavelmente o motivará para continuar seus estudos. Além disso, toda essa tecnologia encontra-se circunscrita na vida pessoal do aluno brasileiro, o que confere um grau de familiaridade, segurança e interesse.

\section{CONCLUSÃO}

Enquanto as dificuldades relativas ao aprendizado da língua japonesa por brasileiros forem tomadas como motivo único para a desmotivação dos aprendizes, pouco se pode fazer no sentido de tratar deste problema. Ao invés disso, propomos que as dificuldades do aprendizado do japonês devam ser enfrentadas através de uma cuidadosa articulação do conteúdo a ser ensinado a partir de um eixo baseado em gêneros discursivo-textuais. Os gêneros são uma excelente alternativa ao atual eixo estruturalista-gramatical, uma vez que eles facilitam ao mesmo tempo tanto o acesso à língua de forma autêntica, quanto a demarcação de objetivos claros por parte de professores e alunos. Assim, torna-se possível decidir quais são as questões gramaticais de fato relevantes para a comunicação circunscrita a determinado gênero, organizar itens lexicais tematicamente, além de oferecer a possibilidade de trabalhar com aspectos hoje virtualmente esquecidos nos materiais didáticos - estrutura textual, informações extra-textuais e questões culturais relevantes para o gênero em questão. $\mathrm{O}$ ensino de ideogramas também pode se beneficiar grandemente desta 
organização, uma vez que torna-se possível agrupá-los por relevância a gêneros específicos, ao invés da usual preocupação com a facilidade de escrita dos mesmos.

$\mathrm{O}$ uso extensivo de tecnologias digitais adequa-se muito bem nesta nova proposta de organização de conteúdo por diversas razões: facilitam o acesso e utilização de material autêntico (como programações de cinema e propagandas); utilizam ferramentas do dia-a-dia com as quais o aluno já está familiarizado e que de fato poderá necessitar para realizar tarefas na língua-alvo (como mapas virtuais e aplicativos de celulares); não requerem que o aluno escreva à mão os ideogramas japoneses, mas, assim como acontece no próprio Japão de hoje, exigem apenas a "escrita digital" (através do teclado do computador ou do celular); tornam mais fácil a interação com falantes nativos da língua (através de redes sociais, por exemplo); e permitem o acesso à cultura japonesa (na forma de vídeos e textos, por exemplo).

À medida que o aprendiz avançar em um curso organizado de tal maneira, acreditamos que sua motivação intrínseca será constantemente renovada, uma vez que ele experimentará, durante todo o processo, interações reais e significativas, e saberá que está progressivamente tornando-se proficiente na língua japonesa.

\section{REFERÊNCIAS}

3A CORP. Minna no Nihongo, Book 1, Japanese Edition. 3A Corp, 1998.

BOMCHOVITCH, E. Estratégias de aprendizagem e desempenho escolar: considerações para a prática educacional. Psicologia: Reflexão e Crítica, $n^{\circ} 2$ (2), 1999. 361-367.

BROWN, H.D., Teaching by principles: an interactive approach to language pedagogy . $2^{\text {nd }}$ Edition, San Franscico State University, 2000.

DECI, E.L. Intrinsic Motivation. New York: Plenum Press, 1975.

DECI, E.L. e RYAN, R.M. Intrinsic and Extrinsic Motivations: Classic Definitions and New Directions. Contemporary Educational Psychol, $n^{\circ} 25,2000$. 54-67.

KRAMSCH, C. Context and culture in language teaching. Oxford University Press, 2003. p. 175.

KUSAKARI, M.; TERAUCHI, K.; SHIRAI, K. Nihongo 1, 2, 3 Jo no ni. Aruku, 1996. 
LENS, W.; MATOS, L.; VANSTEENKISTE, M. Professores como fonte de motivacional dos alunos: $\mathrm{O}$ quê e o porquê da aprendizagem do aluno. Educação, n. ${ }^{0} 31$ (1), p. 17-20, 2008.

MARCUSCHI, L.A. Gêneros Textuais, Mídia e Ensino de Língua. São Paulo: Cortez, 2002.

MARCUSCHI, L.A. Gêneros Textuais: definição e funcionalidade. In: DIONISIO, Angela Paiva; MACHADO, Anna Rachel; BEZERRA, Maria Auxiliadora. (Org.) Gêneros Textuais e Ensino. 4. Ed. Rio de Janeiro: Lucena, 2005. p. 233.

SWALES, J. Genre Analysis. English in Academic and Research Settings. Cambridge: CUP, 1990.

\section{O AUTOR}

Flávio Ricardo Medina de Oliveira, Mestre, Universidade Federal do Paraná E-mail: flaviormedina@gmail.com 